\title{
The Influence of Parent-Child Relationship on the Academic Pressure of Elementary Students: A Moderated Mediation Model \\ -Based on the Survey and Analysis of 38,069 Elementary Students
}

\author{
Mingyue Liao, ${ }^{1}$ Ronghua Ying, ${ }^{1}$ Shike Zhou ${ }^{2}$
}

1. Nanjing Normal University, Nanjing 210097, Jiangsu, China

2. Jiangsu Academy of Educational Science, Nanjing 210013, Jiangsu, China

\begin{abstract}
Taking the elementary students of grade 5 in Jiangsu Province as the object, the research is carried out on the family and peer factors that affect the academic pressure of elementary students. The results show that parent-child relationships and peer relationships are critical protective factors for elementary students' academic pressure. The parent-child relationship negatively predicts the academic pressure and affects its academic pressure through the peer relationship, while self-esteem regulates the relationship between the peer relationship and the academic pressure. The study results suggest that constructing a good parent-child relationship and peer relationship while improving children's selfesteem positively impacts elementary students to cope with academic pressure.
\end{abstract}

Science Insights Education Frontiers 2021; 9(1):1161-1182.

Doi: 10.15354/sief.21.or035

How to Cite: Liao, M., Ying, R., \& Zhou, S. (2021). The influence of parentchild relationship on the academic pressure of elementary students: A moderated mediation model-Based on the survey and analysis of 38,069 elementary students. Science Insights Education Frontiers, 9(1):1161-1182.

Keywords: Elementary Students, Academic Pressure, Parent-Child Relationship, Peer Relationship, Self-Esteem 
Liao et al. Parent-Child Relationship and Academic Pressure in Elementary Students.

About the Authors: Mingyue Liao, Candidate of Master's Degree in Development and Educational Psychology, Jiangsu Key Laboratory of Mental Health and Cognitive Science, School of Psychology, Nanjing Normal University, Nanjing 210097, Jiangsu, China. E-mail: liaomingyueyes@163.com

Shike Zhou, Senior Teacher, Middle School Teaching and Research Office, Jiangsu Academy of Educational Sciences, Nanjing 210013,Jiangsu, China.E-mail: jyszsk@163.com

Correspondence to: Ronghua Ying, Jiangsu Key Laboratory of Mental Health and Cognitive Science, School of Psychology, Nanjing Normal University, Nanjing 210097, Jiangsu, China. E-mail: 13951969343@163.com

Funding: This study was supported by the major research project of the Ministry of Education's philosophy and social science research. The phased achievement of "Research on the Evaluation Index System of High-quality Education Development" (Project \#: 20JZD053).

Conflict of Interests: None.

(C) 2021 Insights Publisher. All rights reserved.

Creative Commons Non Commercial CC BY-NC: This article is distributed under the terms of the Creative Commons Attribution-NonCommercial 4.0 License (http://www.creativecommons.org/licenses/by$\mathrm{nc} / 4.0 /$ ) which permits non-commercial use, reproduction and distribution of the work without further permission provided the original work is attributed by the Insights Publisher. 


\section{Question}

CADEMIC pressure is the various stimuli from the environment that students
endure in the learning process and the resulting physical, psychological, and
socially behavioral reflections. It has been widely concerned by scholars in education and psychology for a long time. Based on many previous studies, it is generally believed that academic pressure includes both subjective and objective aspects: one is the accurate load of learning, and the other is the physical discomfort and psychological pressure caused by the students facing their tasks (Long et al., 2013), and the latter is our preferred factor in this study. Too high academic pressure will negatively affect academic performance, volition control (Pan et al., 2016), and sleep quality (Dou et al., 2019); and easily cause negative emotions such as anxiety and depression in students (Liu \& Tao, 2005). Severe academic pressure can also lead to academic burnout (Zhu \& Wang, 2009) and even negative behavioral tendencies such as self-harm and suicide (Zhang et al., 2016; Ang \& Huan, 2006). It can be seen that excessive academic pressure has negative effects on children's physical and mental health. In the past few years, more attention has been paid to the academic pressure of middle school students and college students (Li et al., 2019; Lin et al., 2020). In recent years, with the increasingly fierce competition, the notion of "not letting children lose at the starting line" has taken root in people's hearts. Children begin to bear the multiple expectations of parents, teachers, and society from the elementary level. Even if repeated requests are made to reduce the burden on students, the phenomenon of excessive academic pressure on elementary students still exists. Studies have found that contemporary elementary students most often experience negative life events with academic performance as the mainstay (Yu \& Chen, 2001), and their academic pressure level is generally on the rise (Wu, 2019) and has exceeded the appropriate level (Huang \& Wang, 2020). What is more worthy of vigilance is that academic pressure, which has been increasing in recent years, has become a significant risk factor that causes elementary students' destructive emotions, problematic behaviors, and even suicidal behaviors (Chen et al., 2010; Zheng et al., 2001; Li, 2020). Therefore, reducing the burden must start with reducing the pressure, or reducing the pressure is the essence of reducing the burden. From developmental psychology, elementary school is the beginning of an individual's formal entry into school for systematic learning and a crucial period for personal physical and mental growth and personality development. Therefore, an in-depth discussion on the influencing factors and mechanisms of elementary students' academic pressure is of great value. This will provide theoretical and data support for elementary students' physical and mental health development and elementary education and better guide practical work.

The parent-child relationship refers to the relationship between parents and children. It is the earliest interpersonal relationship established by children, involving two dimensions of intimacy and conflict (Li et al., 2015). Attachment theory (Fisher, 1974) believes that a good parent-child relationship plays a fundamental role in individual adaptation and development; conversely, a poor parent-child relationship may expose it to more risks. Studies have shown that a good parent-child relationship is an 
essential factor in promoting children's healthy development, and parents are protective factors for children to alleviate behavioral adaptation problems (Xie, 2020; Wang et al., 2018). On the contrary, a bad parent-child relationship can lead to difficulties in adapting to teenagers and negatively affect their development (Zou et al., 2010). Studies have shown that the parent-child relationship is one of the important factors affecting students' academic pressure. Parents' severe punishment of their children, overprotection, and refusal to deny are strong predictors of academic pressure (Luo, 2019; Wang et al., 2012). A good parent-child relationship has a significant preventive and interventional effect on the academic pressure of students (Mulyadi et al., 2016). However, the longitudinal study of scholars such as Kim found that the closer the parent-child relationship, the greater the academic pressure of the child (Kim \& Lee, 2013). According to the pressure buffer model proposed by Sheldon et al., an excellent social support network can provide people with stable and active support, and sufficient social support resources can strengthen the individual's ability to cope with pressure, thereby preventing individuals from perceiving high levels of pressure (Cohen \& Wills, 1985). The primary source of social support for elementary school children is the family, and good family support can buffer pressure (Wei et al., 2018).

Although there are many studies on family factors affecting children's pressure, most of them are based on parental rearing styles and family functions (Liao, 2015; Hua, 2018), and there are few studies on the internal mechanism of the parent-child relationship affecting children's academic pressure. How the parent-child relationship affects academic pressure (a moderated mechanism) and under what conditions affect academic pressure (mediation mechanism) remains further explored. Secondly, in previous studies, insufficient attention has been paid to the indirect role of other factors (such as peer relationships) between parent-child relationship and academic pressure, and research on the regulation of individual susceptibility factors/protective factors is also lacking.

According to the ecological system theory of human development, family and peers are two important micro-systems that affect children's development (Bronfenbrenner, 1992). As children enter school collective life, the influence of peers on individuals is becoming increasingly prominent. Studies have shown that the peer relationship of elementary students in grades 3-6 is superior to the parent-child relationship (Dong \& Wo, 2005). Peer relationship is a kind of common activity and mutual cooperation relationship between children of the same or similar age, or mainly refers to a sort of interpersonal relationship established and developed in communication between peers or individuals with the same level of psychological development (Yang, 2008). Studies have shown that peer friendship and the frequency of peer interaction are negatively correlated with academic pressure (Li et al., 2019; Wu \& Xiang, 2020), while peer infringement is positively correlated with academic pressure (Zhang et al., 2015). A good peer relationship helps reduce negative emotions such as anxiety, depression, and stress (Zhang et al., 2019). It can be seen that the peer relationship is closely related to the academic pressure of children. 
The establishment of a good peer relationship may be related to a person's parent-child relationship. As the first interpersonal relationship with the longest duration in an individual's life, the parent-child relationship has an important impact on the individual's peer relationship (Ye \& Pang, 1999). Many studies had paid attention to the comprehensive effects of family factors and peer factors on children (Lin et al., 2008; Liu et al., 2019). Although these studies were still controversial, these results supported the indirect effect model of the parent-child relationship and peer relationship on children's problem behaviors. This model emphasized the fundamental role of the parentchild relationship and believed that the parent-child relationship is the foundation for the establishment and development of the peer relationship, which indirectly affected the behavioral adaptation of children through the peer relationship (Tian \& Tian, 2014). De Goede et al. believed that the perception of the parent-child relationship will affect children's perception of the peer relationship (De Goede, I. H., et al., 2009). A good parent-child relationship could promote individuals to establish and maintain positive, close and extensive friendships (Yu \& Zhou, 2004). Unfavorable parent-child relationships caused children to lose the emotional and trust basis for interpersonal communication, lack the necessary cognitive and social skills (Zheng \& Cen, 2006), and are not conducive to children's establishment and development of a good peer relationship. Many other studies had shown that peer factors are in line with the indirect effect model in the influence mechanism of parent-child on adolescents' negative emotions, subjective well-being, loneliness, depression, and risk-taking behaviors (Wang et al., 2016; Zhang et al., 2019; Tian et al., 2014); however, there is still a lack of research on the subject of academic pressure that jointly examines the roles of the two.

The individual-environment interaction model points out that individual behavior is formed and developed in the interaction between the individual and the environment (Chen et al., 2015). Therefore, the discussion on the internal mechanism of children's academic pressure should examine the environmental factors (parent-child relationship, peer relationship, etc.) and discuss the influence of individual elements. Selfesteem is often referred to as the core of mental health, a "buffer" and "filter" for destructive emotions. It is significantly negatively correlated with bad moods such as anxiety and depression that damage mental health (Zhang et al., 2015), and stress is usually one of the causes of bad moods such as anxiety and depression (Wu et al., 2009). As far as the peer relationship is concerned, self-esteem has a significant positive correlation with the peer relationship (Lai et al., 2008), and self-esteem can clearly predict the peer relationship (Liu et al., 2016). Individuals with high self-esteem have a positive attitude towards self-ability and value (Cai et al., 2011) and have better self-regulation ability (Setliff \& Marmurek, 2002), and adaptability (Wu et al., 2009); and they tend to be confident and proactive in communicating with the outside world, and it is easy to get the goodwill of their peers. Compared with individuals with low self-esteem, they are more likely to have good interpersonal relationships (Baumeister et al., 2003) and obtain peer support and friendship.

In summary, as important variables in the two micro-systems of family and peer, parent-child relationship and peer relationship have an important impact on the 
development and adaptation of adolescents. However, previous studies on the influence of family and peers on academic pressure only focused on one of them. There are few relevant supporting studies on the impact of the combination of the two on the academic pressure of elementary students, resulting in a large number of results "independently" and relatively fragmented (Tian \& Tian, 2014). Therefore, it is necessary to deeply explore the mechanism of the two effects on learning pressure, which is also the focus of this research. In addition, previous studies have mainly focused on the buffering effect of self-esteem between stress and adaptability problems (Wu et al., 2009). In contrast, less direct attention has been paid to the regulating effect of self-esteem on stress. Therefore, under the influence of the ecosystem theory, based on the "individualenvironment interaction view," this study intends to start from the parent-child relationship and peer relationship between the individual's self-esteem and the environment in which it is located, to examine both the individual and the environment impact on children's academic pressure. Based on the "stress buffer model" of self-esteem, individuals with high self-esteem have more resources to help them cope with destructive emotions and difficulties. This study proposed that self-esteem has a regulating effect on stress. In short, this study intends to construct a moderated mediation model and examine the influence of family factors (parent-child relationship), peer factor (peer relationship), and individual factor (self-esteem) on children's academic pressure. Specifically, this study will investigate the modulator (How does the parent-child relationship work?) and mediation (When does the parent-child relationship work?) mechanisms of parentchild relationships that affect children's academic pressure based on a large sample of 38,069 elementary students. And explore the mediating role of peer relationship and self-esteem's regulation of the mediation chain to provide empirical support and theoretical guidance for the prevention and intervention of children's academic pressure. In summary, we can speculate that peer relationships and self-esteem may have a mediating role between parent-child relationships and academic pressure. The model is shown in Figure 1.

This study puts forward the following hypotheses: (1) The parent-child relationship, as a protective factor of academic pressure, can negatively predict academic pressure. (2) The parent-child relationship may indirectly affect the academic pressure through the peer relationship, that is, the peer relationship is likely to play an intermediary role between the parent-child relationship and the academic pressure. (3) Selfesteem plays a regulatory role in the path of "peer relationship-academic pressure."

\section{Methodology}

\section{Research Objects}

Since 2006, Jiangsu Province has gradually established an academic quality monitoring system for basic education students in the province. Every two years, the academic level of elementary and middle school students is tested, and data related to students' academic performance is collected through questionnaire surveys; the scope of the study 


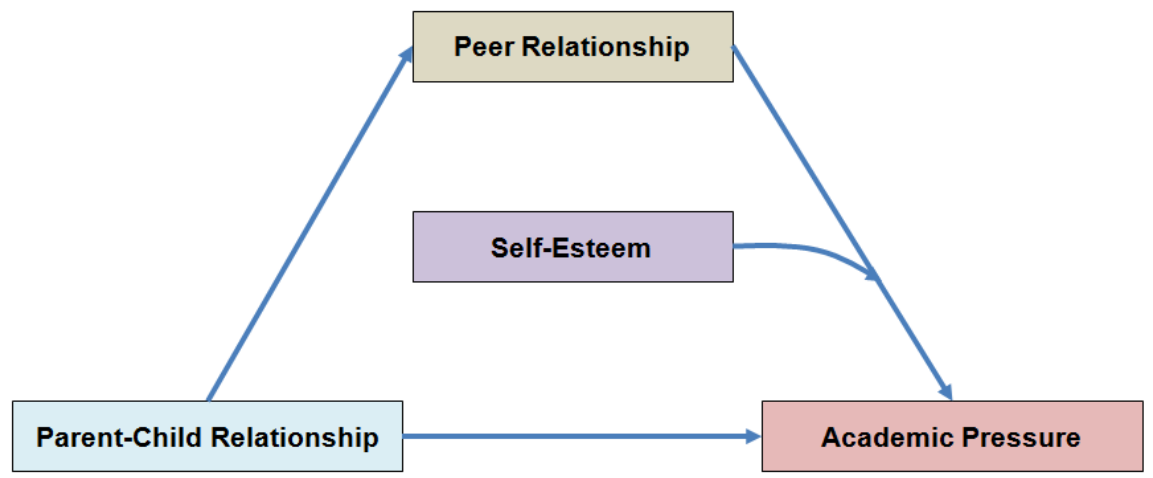

Figure 1. The hypothesis of the Moderated Mediation Model.

includes randomly selected students and teachers, and school leaders of their schools. The data used in this study comes from the 2018 basic education student academic quality monitoring data in Jiangsu Province. The test adopted a two-stage stratified sampling method to conduct random tests and surveys on elementary and middle school students. Among them, the elementary school randomly checked the fifth-grade students of 1,725 schools. After excluding samples with missing main variables and apparent errors in the answers, 38,069 samples were finally included in the analysis. The effective subjects were 19,831 males and 18,238 females; 18,911 were only one child, and 19,158 were non-only-one children.

\section{Research Tools}

\section{Parent-Child Relationship}

Use self-compiled five items, namely "I feel happy with my parents," "I will share my secrets and personal feelings with my parents," "My parents and I will argue with each other or blame each other," "When I encounter problems, my parents will help me solve it," and "I will do something happy with my parents." Each item is scored with 5 points ( 1 "never" $\rightarrow 5$ "always"). Item 3 is reverse scoring. The higher is the scale score, the higher is the parent-child relationship level. Use AMOS 22.0 for confirmatory factor analysis (the same below). The fitting results are obtained: $x^{2} / \mathrm{df}=163.65, \mathrm{RMSEA}=$ $0.065, \mathrm{CFI}=0.982$, TLI $=0.963$. The results show that the questionnaire fits well. The $\alpha$ coefficient of the questionnaire was 0.65 .

\section{Peer Relationship}

Use self-compiled five items, namely "I am happy when I am with my classmates," "I often quarrel with my classmates," "I can find friends when I need them," "Classmates like me very much," and "It's hard to make others like me." Each item is scored with 5 
points ( 1 "disagree" $\rightarrow 5$ "agree"). Among them, the second and third items are scored in reverse. The higher is the scale score, the higher is the peer relationship level. Using factor analysis, the question "I often quarrel with my classmates" was deleted. The remaining four questions fit well: $x^{2} / \mathrm{df}=13.96$, RMSEA $=0.018, \mathrm{CFI}=0.999$, $\mathrm{TLI}=0.995$. The $\alpha$ coefficient of the questionnaire was 0.65 .

\section{Self-Esteem}

Use self-compiled five items, namely "I feel I have many advantages," "I feel that I am a loser," "I can do things well like most people," "In general, I am Satisfied," and "I often feel that I am useless." Each item is scored with 5 points (1 "Agree" $\rightarrow 5$ "Disagree"). Among them, the second item is reverse scoring. The higher is the scale score, the higher is the level of self-esteem. In this study, the questionnaire fits well: $x^{2} / \mathrm{df}=$ 120.43, RMSEA $=0.056, \mathrm{CFI}=0.990, \mathrm{TLI}=0.967$. The $\alpha$ coefficient of the questionnaire is 0.66 .

\section{Academic Pressure}

Six self-compiled items are used, namely "the amount of homework," "the difficulty of the homework," "the number of tests and examinations," "if the school announces the results and rankings, how do you feel," "I feel that during class Nervous," and "Every time I take an exam, I'm always worried that I cannot do well." Each item uses a fivepoint scoring. The higher the scale score, the higher the academic pressure. In this study, the questionnaire fits well: $x^{2} / \mathrm{df}=201.48, \mathrm{RMSEA}=0.073, \mathrm{CFI}=0.977, \mathrm{TLI}=0.915$. The $\alpha$ coefficient of the questionnaire is 0.66 .

\section{Data Analysis}

Use SPSS25.0 to calculate descriptive statistics, correlation coefficients, and internal consistency reliability analysis of each variable. Use AMOS22.0 to perform confirmatory factor analysis on each variable. Use the SPSS macro program PROCESS to carry out moderated mediation analysis.

\section{Common Method Deviation Test}

Harman's single factor method was used to test the common method deviation (Zhou \& Long, 2004). In the test, all items related to the four variables of the parent-child relationship, peer relationship, self-esteem, and academic pressure are used for exploratory factor analysis to extract a factor. It was found that the explanatory rate of the firstfactor variable was $22.19 \%$, which was less than $40 \%$, indicating that there is no serious common method bias problem in this study.

\section{Results}




\section{Descriptive Statistics and Related Analysis of Each Vari- able}

Pearson correlation analysis is performed on the scores and gender of elementary students in the parent-child relationship, peer relationship, self-esteem, academic pressure, and whether they are the only child. The results are shown in Table 1. Both parent-child relationship and peer relationship are significantly negatively correlated with learning pressure, indicating that they are both protective factors for learning pressure; parentchild relationship and peer relationship are significantly positively correlated, indicating that independent variables and intermediate variables are relatively independent and suitable for doing a subsequent test of mediation effect. At the same time, the correlation between self-esteem and peer relationship, and academic pressure is significant. The peer relationship is positively correlated with self-esteem, and academic pressure is negatively correlated with self-esteem, which is suitable for subsequent moderating effect testing (Wen et al., 2005). In addition, the results showed that gender and whether an only child is significantly related to the parent-child relationship, peer relationship, self-esteem, and academic pressure. In view of the fact, the existing studies have found that the depression of only children is higher than that of non-only children (Fan, 2014), academic pressure is an important factor in the development of depression in Chinese adolescents (Hou \& Chen, 2016). Therefore, this study takes the only child or not as a control variable into the model. In addition, studies have found that gender is an important individual factor affecting the development of adolescents' self-esteem (Pan, 2015). Girls are more likely to perceive higher stress than boys (Ma, 2014). Therefore, this study also included gender as a control variable in the model.

\section{The Influence of Parent-Child Relationship, Peer Rela- tionship, and Self-Esteem on Academic Pressure}

To test whether there is a moderating mediation model for the influence of the parentchild relationship on academic pressure, we first tested the mediating role of the peer relationship between parent-child relationship and academic pressure. Based on the above analysis, it is found that the relationship between parent-child relationship, peer relationship, and academic pressure meets the conditions for mediating effect analysis. Therefore, model 4 in the PROCESS program developed by Hayes is used to analyze the mediating effect (Bolin, 2014), and gender and whether to be alone are included in the control variables for analysis. As shown in Table 2, the parent-child relationship can negatively predict the academic pressure of elementary students $(\beta=-0.28, t=-$ $56.29, p<0.001)$, and positively predict the peer relationship $(\beta=0.37, t=78.26, p<$ $0.001)$. The peer relationship can negatively predict academic pressure $(\beta=-0.20, t=-$ 38.62, $p<0.001)$. The Bootstrap 95\% interval of the direct effect of the parent-child relationship on academic pressure and the indirect effect of peer relationship does not 
Table 1. Descriptive Statistics and Correlation Analysis Results of Each Variable $(n=38,069)$.

\begin{tabular}{|c|c|c|c|c|c|c|c|c|}
\hline Variable & $\mathrm{M} \pm \mathrm{SD}$ & Min (Max) & 1 & 2 & 3 & 4 & 5 & 6 \\
\hline 1 Gender & $1.48 \pm 0.50$ & $1(2)$ & 1.00 & & & & & \\
\hline 2 Only-one Child & $1.50 \pm 0.50$ & $1(2)$ & $0.03^{* *}$ & 1.00 & & & & \\
\hline $\begin{array}{l}\text { Parent-Child } \\
\text { Relationship }\end{array}$ & $21.17 \pm 3.79$ & $5(25)$ & $0.04^{* *}$ & $-0.07^{* *}$ & 1.00 & & & \\
\hline 4 Peer Relationship & $17.47 \pm 3.13$ & $4(20)$ & $0.10^{\star *}$ & $-0.07^{* *}$ & $0.38^{\star *}$ & 1.00 & & \\
\hline 5 Self-Esteem & $21.13 \pm 4.13$ & $5(25)$ & $0.03^{* *}$ & $-0.08^{* *}$ & $0.37^{* *}$ & $0.46^{* *}$ & 1.00 & \\
\hline 6 Academic Pressure & $16.87 \pm 3.63$ & $6(30)$ & $-0.01^{*}$ & $0.04^{* *}$ & $-0.28^{* *}$ & $-0.28^{* *}$ & $-0.32^{* *}$ & 1.00 \\
\hline
\end{tabular}

Note: Gender1 = Male, Gender2 = Female; Only-One Child1 $=$ Yes, $2=$ No. ${ }^{*} p<0.05,{ }^{* *} p<0.01$, two-tailed test.

Table 2. Regression Analysis (Standardization) of the Mediating Model of Peer Relationship between Parent-Child Relationship and Academic Pressure.

\begin{tabular}{lllllll}
\hline \multirow{2}{*}{ Variable } & \multicolumn{2}{c}{ Academic Pressure } & \multicolumn{2}{l}{ Peer Relationship } & \multicolumn{2}{l}{ Academic Pressure } \\
\cline { 2 - 7 } & $\boldsymbol{\beta}$ & $\boldsymbol{t}$ & $\boldsymbol{\beta}$ & $\boldsymbol{t}$ & $\boldsymbol{\beta}$ & $\boldsymbol{t}$ \\
\hline Gender & -0.01 & -0.52 & 0.18 & $18.94^{* * *}$ & 0.03 & $3.21^{* *}$ \\
\hline Only-One Child & 0.04 & $4.13^{* * *}$ & -0.09 & $-9.33^{* * *}$ & 0.02 & $2.36^{*}$ \\
\hline Parent-Child Relationship & -0.28 & $-56.29^{* * *}$ & 0.37 & $78.26^{* * *}$ & -0.20 & $-38.88^{* * *}$ \\
\hline Peer Relationship & & & & -0.20 & $-38.62^{* * *}$ \\
\hline$R^{2}$ & 0.08 & 0.15 & 0.11 & $1215.22^{* * *}$ \\
\hline$F$ & $1080.68^{* * *}$ & $2271.90^{* * *}$ & & & \\
\hline
\end{tabular}

Note: ${ }^{*} p<0.05,{ }^{* *} p<0.01,{ }^{* * *} p<0.001$, two-tailed test. Each variable in the model adopts the standardized variable.

Table 3. A Test of the Mediating Role of Peer Relationship in Parent-Child Relationship and Academic Pressure.

\begin{tabular}{llllll}
\hline & & & Boot Cl & Boot Cl & \\
\cline { 4 - 5 } Effect Type & Effect Size & Boot SE & Lower Limit & Upper Limit & Relative Effect Ratio \\
\hline Overall Effect & -0.278 & 0.005 & -0.288 & -0.268 & $100.00 \%$ \\
\hline Direct Effect & -0.203 & 0.006 & -0.214 & -0.192 & $72.99 \%$ \\
\hline Indirect Effect & -0.075 & 0.002 & -0.080 & -0.070 & $26.98 \%$ \\
\hline
\end{tabular}

Each variable in the model adopts the standardized variable. 


\section{Table 4. Moderated Mediation Model.}

\section{Regression Equation}

\begin{tabular}{|c|c|c|c|c|c|}
\hline Outcome Variable & Predictor Variable & $\beta$ & $t$ & $R^{2}$ & $\boldsymbol{F}$ \\
\hline \multirow{3}{*}{ Peer Relationship } & Gender & 0.179 & $18.941^{* * *}$ & \multirow{3}{*}{0.152} & \multirow{3}{*}{$2271.899^{* *+}$} \\
\hline & Only-One Child & -0.088 & $-9.335^{\star \star \star}$ & & \\
\hline & Parent-Child Relationship & 0.371 & $78.265^{* * \star}$ & & \\
\hline \multirow{6}{*}{ Academic Pressure } & Gender & 0.024 & $2.497^{*}$ & \multirow{6}{*}{0.146} & \multirow{6}{*}{$1084.557^{\star \star \star x}$} \\
\hline & Only-One Child & 0.003 & 0.338 & & \\
\hline & Parent-Child Relationship & -0.157 & $-29.891^{* * *}$ & & \\
\hline & Peer Relationship & -0.139 & $-24.049^{* * t}$ & & \\
\hline & Self-Esteem & -0.214 & $-38.178^{* * *}$ & & \\
\hline & Peer Relationship $\times$ Self-Esteem & -0.036 & $-8.842^{* \star \star}$ & & \\
\hline
\end{tabular}

Note: ${ }^{*} p<0.05,{ }^{* *} p<0.01,{ }^{* *} p<0.001$, two-tailed test. Each variable in the model adopts the standardized variable.

contain 0 (see Table 3), indicating that the peer relationship plays a part of the mediating role between parent-child relationship and academic pressure.

Secondly, model 14 is used to analyze the moderated mediation model, and gender and only child are included as control variables. The results are shown in Table 4. After putting self-esteem into the model, peer relationship significantly negatively predicts academic pressure $(\beta=-0.139, t=-24.049, p<0.001)$, and the product term of peer relationship and self-esteem has a significant effect on the prediction of academic pressure $(\beta=-0.036, t=-8.842, p<0.001)$. This shows that self-esteem has a significant moderating effect on peer relationships and academic pressure.

According to the mediating effect analysis results with moderation, gender and whether the only-one child is the control variables and the specific path coefficients between the variables are shown in Figure 2.

To specifically reveal the magnitude and direction of the self-esteem adjustment effect, the self-esteem score is divided into "high self-esteem group" and "low self-esteem group" based on the mean \pm 1 standard deviation (SD), and a simple slope analysis is performed (Simple slope analysis), the results show (see Figure 3). Under low self-esteem conditions (one SD below the average), peer relationship has a significant negative predictive effect on academic pressure $(\beta=-0.10, t=-16.97, p<0.001)$; under high self-esteem conditions (one SD higher than the average), the peer relationship still has a significant negative predictive effect on academic pressure $(\beta=-0.17, t=$ $-22.29, p<0.001$ ), but the predictive effect is greater at this time.

\section{Discussion}

This study constructed a moderated mediation model based on a larger sample of data. It focuses on the mediating role of the peer relationship between the parent-child rela- 


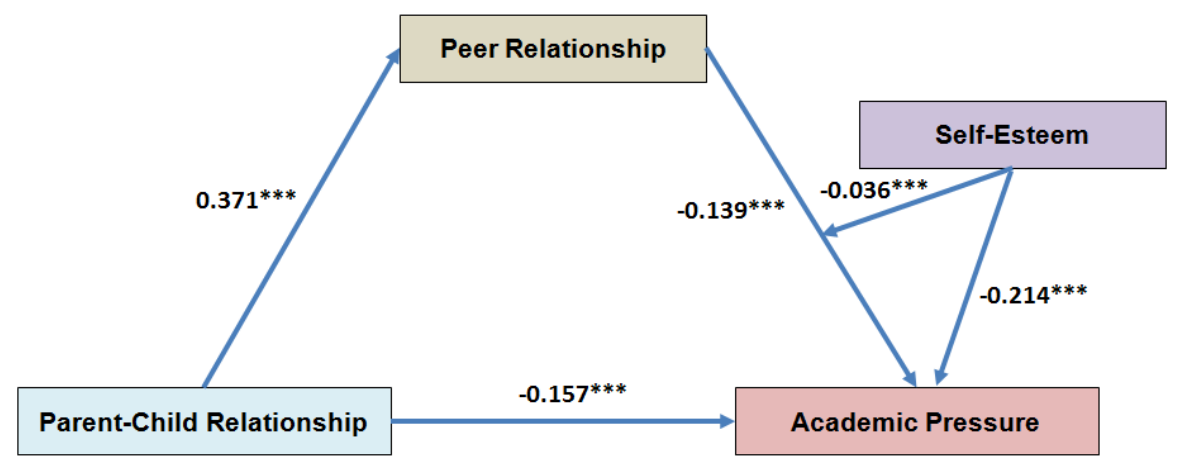

Figure 2. A Diagram of a Moderated Mediating Effect Model.

Note: ${ }^{*} p<0.05,{ }^{* *} p<0.01,{ }^{* * *} p<0.001$, two-tailed test.

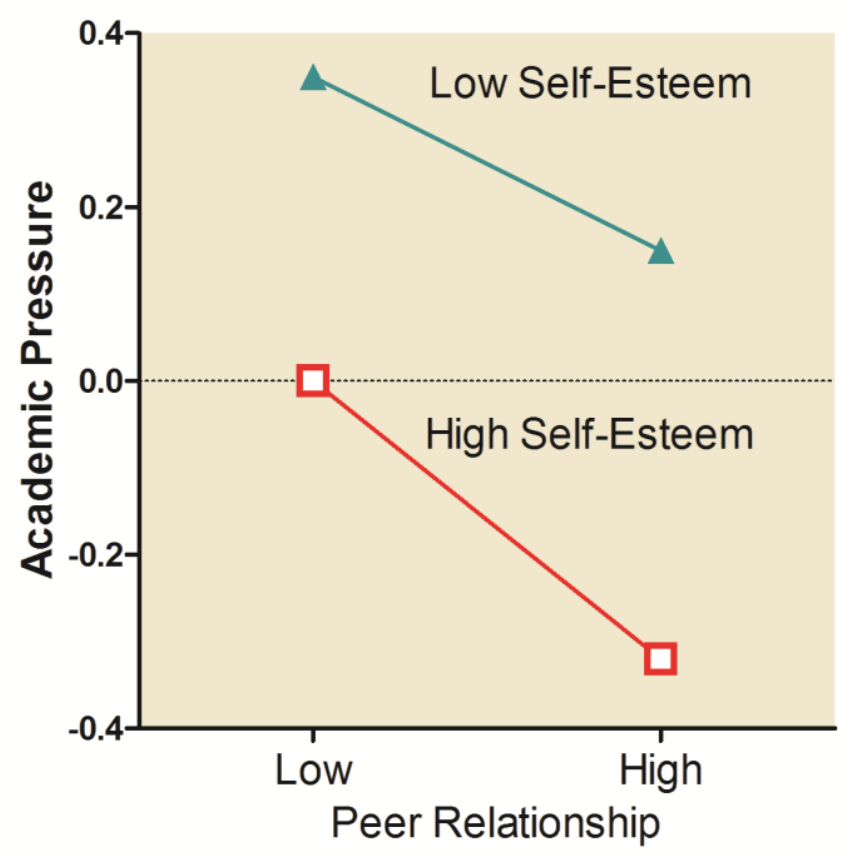

Figure 3. Diagram of the Moderating Effect of Self-Esteem on Peer Relationship and Academic Pressure.

tionship and the child's academic pressure and whether this role is regulated by selfesteem. The research results help to answer what the parent-child relationship passes (how does it work?) And under what conditions (when does it work?), these two key 
issues affect academic pressure. It has specific theoretical and practical significance for future research in this field and preventive intervention of academic pressure.

\section{The Impact of Parent-Child Relationship on Academic Pressure}

The results of this study show that the parent-child relationship of elementary students negatively predicts academic pressure, that is, the better the parent-child relationship, the lower the academic pressure level, which is consistent with most previous research results (Cohen \& Wills, 1985), and once again supports the attachment theory and pressure buffer model. It shows that a good parent-child relationship is a protective factor for elementary students' academic pressure, which can be interpreted as follows: a good parent-child relationship is conducive to the establishment of active parent-child attachment and promotes parent-child communication and family support (Mulyadi et al., 2016). The more proactive the parents are to communicate with their children, the more helpful it is to reduce the children's academic pressure (Xu \& Zhang, 2017). A supportive parent-child relationship from the family can significantly alleviate the negative effects of stress on emotional behavior adaptation (Wang et al., 2018).

However, the aforementioned Kim et al. have reached inconsistent research conclusions. They conducted a 5-year longitudinal study on the parent-child relationship and academic pressure of Korean children. Using a horizontal analysis, they found that the parent-child relationship has a positive effect on academic pressure. Pressure has a negative effect, which is consistent with the horizontal research results in this article. However, the cross-lag analysis found that the parent-child relationship can positively predict the academic pressure of adolescents. The reason for this difference lies in the difference in the design of the two experiments. This research focuses on investigating the correlation between the two, while the study of Kim et al. aims to explore the causal relationship between the two after a long period of data collection. Secondly, the subjects of the two studies are different. The subjects of Kim et al.'s study are middle school students who are in their adolescence, who are more emotionally rich and sensitive; with the increase in academic difficulty, when they cannot meet the expectations of their parents or have a gap with their peers, it is easy to have a strong sense of selfblame and guilt, which in turn increases the sense of academic pressure (Kim \& Lee, 2013). The object of this study is at the elementary school level, and the academic difficulty is relatively low. As long as the parents give some active companionship and the children receive positive support, the perception of academic pressure can be significantly reduced.

\section{The Intermediary Role of Peer Relationship between Parent-Child Relationship and Academic Pressure}


It can be seen from the contents mentioned above that peer factors' introduction helps explain the mechanism through which the parent-child relationship affects children's academic pressure. The results of this study show that the peer relationship plays an intermediary role between the parent-child relationship and the academic pressure, which supports the indirect effect model, that is, the parent-child relationship can also indirectly affect the child's academic pressure through the peer relationship. Children with a high-quality parent-child relationship are more likely to establish and develop a good peer relationship, thereby reducing their academic pressure. This can be explained from the following aspects.

First of all, according to ecosystem theory, a positive parent-child relationship will make children feel respected. Then they have optimistic understandings and expectations of themselves, others, and the surrounding environment. They are willing to associate with people other than their parents and form a more active peer relationship (Ye \& Pang, 1999). On the one hand, a good peer relationship can promote the spontaneous formation of informal learning groups between peers. They share their understanding of knowledge and attitudes towards academic work and can urge each other to complete specific learning tasks together (Fawcett \& Garton, 2005). On the other hand, sharing information between peers reduces the difficulty for individuals to complete academic tasks alone, and the interaction between peers also stimulates children's learning enthusiasm (Ryan \& Shim, 2012), and they feel less academic pressure. Secondly, according to social learning theory, a good peer relationship is the basis for peer relationships. In the process of interacting with peers, children will acquire a series of social skills, social behaviors, attitudes, and experiences, which in turn affect children's social adaptation (Rubin et al., 2007) and better cope with academic pressure. Finally, both the social development model and the primary socialization theory point out a close connection between the background factors of individual development (such as family, peers) (Chen et al., 2015). A good parent-child relationship encourages children to develop good interpersonal relationships and social adaptability, establishing high-quality friendships. Companions help each other, share and discuss academic experiences together, thereby reducing academic pressure.

All in all, the ecological subsystems do not work independently but are interconnected. As revealed by the results of this study, the parent-child relationship and peer relationship, two supportive relationships, can jointly promote academic adaptation (Song \& Wang, 2017). While the parent-child relationship relieves the academic pressure, it can also increase the protective effect of the peer relationship on the academic pressure, thereby increasing the possibility of children being affected by dual protective factors. This result has some enlightenment for the prevention and intervention of children's academic pressure. The prevention and intervention of children's academic pressure should not only start with the simple family, peers, and other factors, but should pay attention to the linking effect of these factors, and pay attention to the different environments of individuals (such as family environment and peer groups) as much as possible. Not only the far-end factors of academic pressure, but also the near-end factors have been taken care of. As far as this research is concerned, we should pay special 
attention to children's peer relationships, communicate in time, give appropriate guidance, and assist children in establishing a positive and mutually helpful peer relationship.

\section{Self-Esteem Adjustment between Peer Relationship and Academic Pressure}

Based on the "individual-environment interaction model," this research constructs a moderated mediation model. We found that self-esteem has a significant regulatory effect in the intermediary chain of "peer relationship - academic pressure." The pressure buffer hypothesis of self-esteem points out that individuals with high self-esteem have more coping resources than individuals with low self-esteem, which helps them to better cope with stressful events. A bad peer relationship may lead to negative interpersonal relationships such as peer rejection, peer rejection, and peer infringement, which can be stressful. Individuals with high self-esteem generally have high self-evaluation and good psychological resilience (Guo \& Ye, 2016), can effectively cope with the impact of a lousy peer relationship, reduce the negative consequences of individuals in a bad peer relationship (Zhao et al., 2016), and actively adapt to school life. On the contrary, children with low or medium self-esteem have poor psychological resilience. It is difficult to find a balance point in the peer relationship, which leads to poor school adaptation (Guo et al., 2005) and increases academic pressure.

\section{Conclusions and Suggestions}

Based on the above research results, we found that good parent-child relationships and peer relationships negatively predict academic pressure. At the same time, children's self-esteem has positive significance for elementary students to cope with academic pressure. Based on this, the moderated mediation model established in this study to explore the factors affecting elementary students' learning pressure has enlightened educators. Specific to the practical level, we suggest: (1) In terms of family, parents of elementary students should strive to adopt active and practical strategies to establish an open and equal parent-child relationship with their children. For example: communicate with children on an equal footing, listen more and less blame, pay more attention to emotions and life, pay attention to children's efforts, and play down excessive attention to academic performance. Such a good parent-child relationship can promote effective parent-child communication. Children are willing to open up their hearts to confide academic pressure to their parents and receive positive feedback and active support from their parents so that they can effectively cope with external pressure and anxiety, promote children's mental health development, and avoid various negative emotions and behaviors caused by academic pressure. (2) In schools, through the development of a variety of class activities, the communication between children and peers can be increased, and the emotional support, information support, and tool support between elementary students can be enhanced (Solomon, 2004), and children's loneliness and so- 
cial anxiety can be alleviated. In short, the effective construction of these two aspects can help elementary students to relieve academic pressure to a greater extent. (3) On the individual side, children's self-esteem has a certain degree of plasticity, increasing the affirmation and support, companionship, and intimacy of children from the three aspects of parents, friends, and teachers (Liu \& Zou, 2007), thereby fostering and enhancing children's self-esteem. This will alleviate the impact of bad peer relationships on academic pressure, and help individuals to self-regulate academic pressure.

\section{Limitations and Perspective}

The starting point of this research design is based on ecosystem theory and development context theory, and the investigation variables are mainly selected from a positive perspective. It aims to explore the parent-child relationship and peer relationship of elementary students and the protective effect of self-esteem on academic pressure. But as far as the source of children's academic pressure is concerned, there is a clear trend of diversification (Chen, 2004). Therefore, in the future, we should also explore the influence of factors such as interpersonal conflict, peer rejection, parental expectations, and teacher-student relationship on academic pressure, or we can also examine the interaction effects of different factors. This will be more conducive to comprehensively revealing the generation mechanism of elementary students' academic pressure to guide educational practice better and promote children's physical and mental health. Secondly, Folkman's stress cognitive interaction model believes that some potential stressors need an individual cognitive assessment before they can become actual stressors, affecting individual psychological or behavioral performance (Folkman et al., 1986). Therefore, in addition to the self-esteem variable investigated in this study, the individual's cognitive evaluation of academic pressure and assessing their resource coping capabilities may also become moderating factors, so they must be fully considered in the future research design. And add relevant elements to the scope of the investigation.

Excessive academic pressure does indeed cause some children's adverse emotional reactions and various bad behaviors, but the pressure itself is also positive. For example, Martin and Marsh (2008) groundbreakingly explored the psychological mechanism of recovery and growth of students under daily academic pressure, which points out the direction for investigating how students under stressful situations can construct active adaptation mechanisms (Zhao \& Yu, 2018). Therefore, in the follow-up research, we can analyze how the dynamic adaptation mechanism under academic pressure is generated? Are there individual differences? These will be more conducive to the transformation and resolution of children's academic pressure and benefit elementary students' physical and mental health. 


\section{References}

Ang, R.P., \& Huan, V.S. (2006). Relationship between academic stress and suicidal ideation: Testing for depression as a mediator using multiple regression. Child Psychiatry \& Human Development, 37(2):133-143. DOI: https://doi.org/10.1007/s10578-006-0023-8

Baumeister, R.F., Campbell, J.D., Krueger, J.I., \& Vohs, K.D. (2003). Does high self-esteem cause better performance, interpersonal success, happiness, or healthier lifestyles? Psychological Science, 4(1):41-44. DOI: https://doi.org/10.1111/1529-1006.01431

Bolin, J.H. (2014). Introduction to mediation, moderation, and conditional process analysis: A regression-based approach. Journal of Educational Measurement, 51(3):335-337. https://www.jstor.org/stable/24018134

Bronfenbrenner, U. (1992). Ecological systems theory. Jessica Kingsley Publishers.

Cai, H., Feng, Y., \& Yue, X. (2011). Pancultural self-esteem needs: Based on research evidence from the Chinese. Advances in Psychological Science, 19(1):1-8. [Chinese] DOI:

https://doi.org/10.3724/SP.J.1042.2011.0000 1

Chen, F., Yang, J., Zhu, Z., Zhou, Q., \& Wang, Y. (2010). A study on the relationship between stress and problem behaviors in the upper grades of primary school students: the moderating effect of coping strategies. Psychological Exploration, 30(4):64-69. [Chinese] DOI:

https://doi.org/10.3969/j.issn.1003$\underline{5184.2010 .04 .013}$

Chen, W., Li, D., Bao, Z., Yan, Y., \& Zhou, Z. (2015). Parent-child attachment, and adolescents' problematic Internet use: a moderated mediation model. Acta Psychologica Sinica, 47(5):611-623. [Chinese] DOI: https://doi.org/10.3724/SP.J.1041.2015.0061 1

Chen, X. (2004). A study on middle school students' academic pressure, coping strategies and coping psychological mechanisms. Dissertation; Chongqing: Southwestern Normal
University. [Chinese]

http://cdmd.cnki.com.cn/Article/CDMD10635-2004085323.htm

Cohen, S., \& Wills, T.A. (1985). Stress, social support, and the buffering hypothesis. Psychological Bulletin, 98(2):310-357. DOI: https://doi.org/10.1037/0033-2909.98.2.310

De Goede, I.H., Branje, S.J., Delsing, M.J., \& Meeus, W.H. (2009). Linkages Over Time Between Adolescents' Relationships with Parents and Friends. Journal of Youth and Adolescence, 38(10):1304-1315. DOI: https://doi.org/10.1007/s10964-009-9403-2

Dong, L., \& Wo, J. (2005). A study on the development characteristics of interpersonal communication among primary school students in grades 3-6. Chinese Journal of Clinical Psychology, 13(1):45-47. [Chinese] DOI: https://doi.org/10.3969/j.issn.10053611.2005.01.014

Dou, F., Wang, M., \& Gao, X. (2019). The effect of learning stress on sleep quality of senior high school students: a regulated mediation model. Chinese Journal of Clinical Psychology, 27(6):1275-1278+1282. [Chinese] DOI:

https://doi.org/10.16128/j.cnki.10053611.2019.06.041

Fan, M. (2014). An empirical study on the impact mechanism of "One Child" policy on health status. Dissertation; Southwestern University of Finance and Economics. [Chinese]

http://cdmd.cnki.com.cn/Article/CDMD10651-1014403198.htm

Fawcett, L.M., \& Garton, A.F. (2005). The effect of peer collaboration on children's problem-solving ability. British Journal of Educational Psychology, 75(2):157-169. DOI: https://doi.org/10.1348/000709904X23411

Fisher, R.L. (1974). Media Review: Books: Attachment and Loss, Separation: Anxiety and Anger. Exceptional Children, 41(1):61-62. DOI: https://doi.org/10.1177/00144029740410011 8 
Folkman, S., Lazarus, R.S., Dunkel-Schetter, C., DeLongis, A., \& Gruen, R.J. (1986). Dynamics of a stressful encounter: Cognitive appraisal, coping, and encounter outcomes. Journal of Personality and Social Psychology, 50(5):992-1003.

https://psycnet.apa.org/buy/1986-21910-001

Guo, B., Wang, Y., \& Zhang, L. (2005). The influence of class environmental variables on the relationship between children's social behavior and school adjustment. Psychological Bulletin, 24(2):233-239. [Chinese]

https://kns.cnki.net/kcms/detail/detail.aspx?d bcode $=$ CJFD $\&$ dbname $=$ CJFD2005\&filenam $\mathrm{e}=$ XLXB20050200A\&v=MmwWrwR2tPsfZ zeLnp2ZgkY9a\%25mmd2B\%25mmd2FAb $\% 25$ mmd2FHAbjkOnTcapfaNfzCMqyWSjS Sh33xK9ayO

Guo, J., \& Ye, Y. (2016). The influence of adolescents' psychological resilience on life satisfaction: The mediating role of self-esteem. Journal of Yulin Teachers College, 37(1):132-135. [Chinese] DOI: https://doi.org/10.13792/j.cnki.cn451300/z.2016.01.025

Hou, J,, \& Chen, Z. (2016). The developmental trajectory of adolescent depression: defining subgroups and their influencing factors. Acta Psychologica Sinica, 48(8):957-968. [Chinese] DOI:

https://doi.org/10.3724/SP.J.1041.2016.0095 $\underline{7}$

Hua, X. (2018). Intervention Research on Youth from Urban Poor Families from the Perspective of Resilience. Dissertation; Guangzhou: South China University of Technology. [Chinese] https://cdmd.cnki.com.cn/Article/CDMD10251-1018224827.htm

Huang, W., \& Wang, Z. (2020). A study on the relationship between primary school pupils' learning pressure and mental health. Journal of Campus Life \& Mental Health, 18(1):3638. [Chinese] DOI: https://doi.org/10.19521/j.cnki.16731662.2020 .01 .010

Kim, E., \& Lee, M. (2013). The reciprocal longitudinal relationship between the parentadolescent relationship and academic stress in Korea. Social Behavior and Personality:
An International Journal, 41(9):1519-1531. DOI:

https://doi.org/10.2224/sbp.2013.41.9.1519

Lai, J., Zheng, G. \& Liu, F. (2008). A study on the influence of peer relationships on the self-esteem of middle school students. Chinese Journal of Clinical Psychology, 16(1):74-76. [Chinese] DOI: https://doi.org/10.3969/j.issn.1005$\underline{3611.2008 .01 .025}$

Li, B., Gao, T., Deng, L., Chen, J., \& Ni, H. (2019). The mediating effect of the core selfevaluation of junior high school students between the class environment and academic pressure-the moderating effect of gender. Psychological Development and Education, 35(2):192-202. [Chinese] DOI: https://doi.org/10.16187/j.cnki.issn10014918.2019.02.08

Li, Y. (2020). Suicidal behaviors of primary and middle school students in Henan Province and its correlation with academic burden. Chinese Journal of School Health, 41(4):539-542. [Chinese] DOI: https://doi.org/10.16835/j.cnki.10009817.2020.04.016

Li, Y., Liu, L., Lyu, Y., Luo, F., \& Wang, Y. (2015). Interpersonal relationship status and problem behaviors of preschool migrant children. Acta Psychology Sinica, 47(7):914927. [Chinese]

https://kns.cnki.net/kcms/detail/detail.aspx?d bcode $=$ CJFD \&dbname $=$ CJFDLAST2015\&fi $\underline{\text { lename }=X L X B 201507008 \& \mathrm{v}=\mathrm{D} \% 25 \mathrm{mmd} 2}$ BIiiu\%25mmd2FODZz6V\%25mmd2FsVqci 1olGOuYY5gxpk\%25mmd2BfPxqYtorhI1h ScWdDNAZuwUZTfZC1yi

Liao, H. (2015). The influence of parental rearing styles on the academic pressure of middle school students. Journal of Neijiang Normal University, 30(4):70-73+78. [Chinese] DOI:

https://doi.org/10.13603/j.cnki.511621/z.2015.04.016

Lin, D., Fang, X., \& Mao, R. (2008). The influence of parent and peer factors on adolescent drinking behavior. Psychological Development and Education, 24(3):36-42. [Chinese] http://www.devpsy.com.cn/CN/Y2008/V24/I $\underline{3 / 36}$ 
Liao et al. Parent-Child Relationship and Academic Pressure in Elementary Students.

Lin, L., Zhang, J., Wang, P., Bai, X., Sun, X., \& Zhang, L. (2020). Perceived control moderates the impact of academic stress on the attention process of working memory in male college students. In Stress: The International Journal on the Biology of Stress, 23(3):256264. DOI:

https://doi.org/10.1080/10253890.2019.1669 557

Liu, C., \& Zou, H. (2007). The relationship between adolescents' social support system and self-esteem. Journal of Psychological Science, 26(3):609-612+534. [Chinese] DOI: https://doi.org/10.16719/j.cnki.16716981.2007.03.022

Liu, G., Zhang, D., Pan, Y., Chen, W., \& Ma, Y. (2016). Research on middle school students' psychological quality and peer relationship: the mediating role of self-esteem. Journal of Psychological Science, 39(6):1290-1295. [Chinese] DOI: https://doi.org/10.16719/j.cnki.16716981.20160602

Liu, L., Tian, L., \& Guo, J. (2019). The influence of parent-child relationship on adolescents' risk-taking behavior: a moderated mediation model. Psychological Development and Education, 35(2):210-218. [Chinese] DOI:

https://doi.org/10.16187/j.cnki.issn10014918.2019.02.10

Liu, X., \& Tao, S. (2005). The role of stress and coping strategies in generating negative emotions among female college students. Acta Psychologica Sinica, 50(5):637-649.

[Chinese] DOI:

https://doi.org/10.3969/j.issn.1007080x.2013.06.015

Long, A., Fan, W., \& Jin, X. (2013). The measurement and attribution model construction of primary and secondary school students' learning stress. Journal of Educational Studies, 9(1):121-128. [Chinese] DOI: https://doi.org/10.14082/j.cnki.16731298.2013.01.016

Luo, J. (2019). The influence of parental rearing styles on high school students' interpersonal pressure and learning pressure. Mental Health Education in Primary and Secondary Schools, 18(36):12-15. [Chinese] https://kns.cnki.net/kcms/detail/detail.aspx?d bcode $=$ CJFD \&dbname $=$ CJFDLASN2019\&f ilename $=$ ZXXK201936005\&v $=$ iaUnAf\% 25 mmd2FHt28IYnyOQJIXG59GYcQQudXR YyH\%25mmd2BAGzTzEtMGmGW7WsW ygL1aG6Mbn2u

Ma, L. (2014). The influence of adolescent selfesteem on different interpersonal relationships. Dissertation; Shaanxi Normal University. [Chinese]

http://cdmd.cnki.com.cn/Article/CDMD10718-1014402656.htm

Martin, A.J., \& Marsh, H.W. (2008). Academic buoyancy: Towards an understanding of students' everyday academic resilience. Journal of school psychology, 46(1):53-83. DOI: https://doi.org/10.1016/j.jsp.2007.01.002

Mulyadi, S., Rahardjo, W., \& Basuki, A.H. (2016). The role of parent-child relationship, self-esteem, academic self-efficacy to academic stress. Procedia-Social and Behavioral Sciences, 217: 603-608. DOI:

https://doi.org/10.1016/j.sbspro.2016.02.063

Pan, B., Zhang, L., Zhang, W. \& Ji, L. (2016). The relationship between adolescents' poor academic performance, academic pressure, and control: a cross-lag study. Psychological Development and Education, 32(6):717-724. [Chinese] DOI: https://doi.org/10.16187/j.cnki.issn10014918.2016 .06 .10

Pan, Y. (2015). A follow-up analysis of junior high school adolescents' self-esteem development trend and influencing factors. Acta Psychologica Sinica, 47(6):787-796. [Chinese] DOI: https://doi.org/10.3724/SP.J.1041.2015.0078 7

Rubin, K. H., Bukowski, W. M., \& Parker, J. G. (2007). Peer Interactions, Relationships, and Groups. Handbook of Child Psychology. John Wiley \& Sons, Inc. 1988.

Ryan, A.M., \& Shim, S.S. (2012). Changes in help-seeking from peers during early adolescence: Associations with changes in achievement and perceptions of teachers. Journal of Educational Psychology, 104(4):1122-1134. DOI: https://doi.org/10.1037/a0027696 
Setliff, A.E., \& Marmurek, H.H. (2002). The mood regulatory function of autobiographical recall is moderated by self-esteem. Personality and Individual Differences, 32(4):761-771. [Chinese] DOI: https://doi.org/10.1016/S0191$\underline{\text { 8869(01)00078-2 }}$

Solomon, P. (2004). Peer support/peer provided services underlying processes, benefits, and critical ingredients. Psychiatric Rehabilitation Journal, 27(4):392-401. DOI: https://doi.org/10.2975/27.2004.392.401

Song, C., \& Wang, J. (2017). The relationship between migrant children's social support and academic pressure: the mediating role of psychological resilience. Psychological Exploration, 37(6):561-566. [Chinese] http://www.cqvip.com/qk/96987x/201706/6 73849950.html

Tian, F., \& Tian, L. (2014). Three models of parent-child relationship and friend relationship affecting problem behavior. Advances in Psychological Science, 22(6):968-976. [Chinese] http://www.cnki.com.cn/Article/CJFDTotalXLXD201406010.htm

Tian, L., Zhang, W., \& Chen, G. (2014). The influence of parental support and friendship quality on loneliness and depression: Testing an indirect effect model. Acta Psychologica Sinica, 46(2):238-251. [Chinese] DOI: https://doi.org/10.3724/SP.J.1041.2014.0023 $\underline{8}$

Wang, H., Xiong, Y., \& Liu, X. (2018). The protective effect of parent-child relationship and friend support on the emotional and behavioral adaptation of migrant children. Psychological Development and Education, 34(5):614-624. [Chinese] DOI: https://doi.org/10.16187/j.cnki.issn10014918.2018.05.12

Wang, Y., Zou, H., Hou, K., Wang, M., Tang, Y., \& Pan, B. (2016). The relationship between parent-child attachment, peer attachment and adolescents' negative emotions: a moderated mediation model. Psychological Development and Education, 32(2):226-235. [Chinese] DOI: https://doi.org/10.16187/j.cnki.issn10014918.2016.02.12
Wang, Z., Xu, X., Li, R., Wang, H., Ren, S., \& An, Q. (2012). The relationship between student mental stress and family factors. Chinese Journal of School Health, 33(8):951-952+955. [Chinese] DOI: https://doi.org/10.16835/j.cnki.1000$\underline{9817.2012 .08 .020}$

Wei, H., Zhou, Z., Zhang, Y. \& Ding, Q. (2018). The relationship between stress and Internet addiction: the moderating effect of family support and friend support. Studies of Psychology and Behavior, 16(2):266-271. [Chinese] DOI:

https://doi.org/10.3969/j.issn.1672$\underline{0628.2018 .02 .018}$

Wen, Z., Hou, J., \& Zhang, L. (2005). Comparison and Application of Moderating Effect and Mediating Effect. Chinese Journal of Psychology, 49(2):268-274. [Chinese] http://www.cnki.com.cn/Article/CJFDTotalXLXB20050200F.htm

Wu, M, Sun, X., Geng, K., \& Ding, Y. (2009). The pressure buffer effect of the stability of adolescents' implicit self-esteem. Journal of Psychological Science, 32(6):13211324+1301.

Wu, M. (2019). An investigation on the learning pressure and influencing factors of urban primary school students. Survey of Education, 8(29):87+89. [Chinese] DOI: https://doi.org/10.16070/j.cnki.cn45$\underline{1388 / \mathrm{g} 4 \mathrm{~s} .2019 .29 .038}$

Wu, W., \& Xiang, X. (2020). The relationship between peer communication and mental health of college students: the mediating role of interpersonal competence. Chinese Journal of Health Psychology, 28(4):585-591. [Chinese] DOI: https://doi.org/10.13342/j.cnki.cjhp.2020.04. $\underline{023}$

Xie, Q. (2020). The relationship between parentchild relationship and mental health of junior high school students in divorced families. Chinese Journal of School Health, 41(7):1019-1021. [Chinese] DOI: https://doi.org/10.16835/j.cnki.10009817.2020.07.017

Xu, Q., \& Zhang, X. (2017). Family socioeconomic status, educational concepts and the academic burden of primary and second- 
ary school students. Chinese Youth Study, 29(6):61-66+81. [Chinese] DOI:

https://doi.org/10.19633/i.cnki.112579/d.2017.06.010

Yang, H. (2008). A new perspective on the relationship between peer relationship and primary school students' academic performance. Journal of Psychological Science, 17(3):648-651. [Chinese] DOI: https://doi.org/10.16719/j.cnki.16716981.2008.03.053

Ye, Z., \& Pang, L. (1999). On the relationship between children's parent-child relationship, peer relationship, and the teacher-student relationship. Psychological Development and Education, 15(4):50-53+57. [Chinese] http://www.devpsy.com.cn/EN/Y1999/V15/I $\underline{4 / 50}$

Yu, G., \& Chen, S. (2001). The relationship between primary school students' life pressure, academic achievement, and adaptive behavior. Acta Psychologica Sinica, 46(4):344-348. [Chinese]

https://www.cnki.com.cn/Article/CJFD2001XLXB200104009.htm

Yu, H., \& Zhou, Z. (2004). Children's Two Kinds of Intimate Interpersonal Relationships: Parent-Child Attachment and Friendship. Journal of Psychological Science, 23(1):143-144. [Chinese] https://www.cnki.com.cn/Article/CJFDTotal -XLKX200401039.htm

Zhang, J., Li, Y., \& Guo, Y. (2016). The correlation between suicide possibility and life events of college students. Chinese Journal of Health Psychology, 24(1):55-58. [Chinese] DOI:

https://doi.org/10.13342/j.cnki.cjhp.2016.01. $\underline{013}$

Zhang, L., Pan, B., \& Ji, L. (2015). The relationship between negative peer relationship, academic pressure and executive function in adolescence. Developmental Psychology Professional Committee of Chinese Psychological Association. Abstract Collection of the 13th Academic Annual Meeting of Developmental Psychology Professional Committee of Chinese Psychological Association. Chinese Psychology Society for the Development of Psychology Professional Commit- tee: School of Psychology, Faculty of Education, Northeast Normal University, 29.

[Chinese] https://cpfd.cnki.com.cn/Article/CPFDTOT AL-DBJX201507001020.htm

Zhang, R., Chen, J., Lei, W., Liang, X., \& Liu, Z. (2019). The mediating effect of interpersonal relationship on loneliness and negative emotions of secondary nursing students. Chinese Journal of Health Psychology, 27(7):11001104. [Chinese] DOI: https://doi.org/10.13342/i.cnki.cjhp.2019.07. $\underline{034}$

Zhang, X., Guo, H., Lin, D. (2019). A study on the relationship between parent-child, peer, teacher-student relationships and adolescents' subjective well-being. Psychological Development and Education, 2019. 35(4):458-466. [Chinese] DOI:

https://doi.org/10.16187/j.cnki.issn10014918.2019.04.09

Zhang, X., Zu, J., \& Zhao, Y. (2015). Theoretical construction and empirical research on self-esteem development of children and adolescents. Psychological Development and Education, 31(1):15-20. [Chinese] DOI: https://doi.org/10.16187/j.cnki.issn10014918.2015.01.03

Zhao, F., \& Yu, G. (2018). Daily academic flexibility: Active adaptation mechanism under daily academic pressure. Advances in Psychological Science, 26(6):1054-1062. [Chinese] DOI:

https://doi.org/10.3724/SP.J.1042.2018.0105 4

Zhao, J., Yang, P., Zhao, X. \& Zhang, W. (2016). Peer abuse and depression in early adolescents: the moderating role of self-esteem and gender. China Journal of Special Education, 23(1):70-75. [Chinese] DOI:

https://doi.org/10.3969/j.issn.10073728.2016.01.011

Zheng, L., Wan, L., \& Li, Z. (2001). Linear regression analysis of the impact of learning pressure on students' mental and physical health. Chinese Journal of School Health, 20(3):224-225. [Chinese] DOI: https://doi.org/10.3969/j.issn.10009817.2001.03.028 
Liao et al. Parent-Child Relationship and Academic Pressure in Elementary Students.

Zheng, X., \& Cen, G. (2006). A review of research on the social development of disadvantaged children in families. Journal of Psychological Science, 43(3):747-751+703. [Chinese] DOI:

https://doi.org/10.16719/j.cnki.1671$\underline{6981.2006 .03 .060}$

Zhou, H., \& Long, L. (2004). Statistical test and control method of common method deviation. Advances in Psychological Science, 22(6):942-950. [Chinese] DOI:

https://doi.org/10.3969/j.issn.1671$\underline{3710.2004 .06 .018}$

Zhu, X., \& Wang, J. (2009). A structural model of the relationship between learning self- efficacy, learning pressure and learning burnout in middle school students. Chinese Journal of Clinical Psychology, 17(5):626628+543. [Chinese]

https://www.cnki.com.cn/Article/CJFDTotal -ZLCY200905034.htm

Zou, H., Li, X., \& Zhang, W. (2010). The characteristics of interpersonal relationships in adolescent families and their mechanism of social adaptation. Journal of Psychological Science, 33(5):1136-1141. [Chinese] DOI: https://doi.org/10.16719/i.cnki.1671$\underline{6981.2010 .05 .056}$ 